\title{
A novel technique for the modeling of shale swelling behavior in water-based drilling fluids
}

\author{
Shaine Mohammadali Lalji ${ }^{1}$ (C) Syed Imran Ali ${ }^{1}$ Zahoor UI Hussain Awan ${ }^{2} \cdot$ Yunus Jawed $^{3}$
}

Received: 25 April 2021 / Accepted: 10 July 2021 / Published online: 6 August 2021

(c) The Author(s) 2021

\begin{abstract}
One of the most significant problems in oil and gas sector is the swelling of shale when it comes in contact with water. The migration of hydrogen ions $\left(\mathrm{H}^{+}\right)$from the water-based drilling fluid into the platelets of shale formation causes it to swell, which eventually increases the size of the shale sample and makes it structure weak. This contact results in the wellbore instability problem that ultimately reduces the integrity of a wellbore. In this study, the swelling of a shale formation was modeled using the potential of first order kinetic equation. Later, to minimize its shortcoming, a new proposed model was formulated. The new model is based on developing a third degree polynomial equation that is used to model the swelling percentages obtained through linear dynamic swell meter experiment performed on a shale formation when it comes in contact with a drilling fluid. These percentages indicate the hourly change in sample size during the contact. The variables of polynomial equation are dependent on the time of contact between the mud and the shale sample, temperature of the environment, clay content in shale and experimental swelling percentages. Furthermore, the equation also comprises of adjustable parameters that are fine-tuned in such a way that the polynomial function is best fitted to the experimental datasets. The MAE (mean absolute error) of the present model, namely Scaling swelling equation was found to be $2.75 \%$, and the results indicate that the Scaling Swelling equation has the better performance than the first order kinetics in terms of swelling predication. Moreover, the proposed model equation is also helpful in predicting the swelling onset time when the mud and shale comes in direct contact with each other. In both the cases, the percentage deviation in predicting the swelling initiation time is close to $10 \%$. This information will be extremely helpful in forecasting the swelling tendency of shale sample in a particular mud. Also, it helps in validating the experimental results obtained from linear dynamic swell meter.
\end{abstract}

Keywords Swelling $\cdot$ Scaling equation $\cdot$ Modeling $\cdot$ Shale $\cdot$ Wellbore instability

All Authors are affiliated from Pakistan Engineering Council (PEC).

Shaine Mohammadali Lalji

shaine@neduet.edu.pk

Syed Imran Ali

engrimran@ neduet.edu.pk

Zahoor Ul Hussain Awan

zahoor@cloud.neduet.edu.pk

Yunus Jawed

j_yunus@ppl.com.pk

1 Department of Petroleum Engineering, NED University of Engineering and Technology, Karachi City, Pakistan

2 Department of Food Engineering, NED University of Engineering and Technology, Karachi City, Pakistan

3 Production Department, Pakistan Petroleum Limited (PPL), Karachi, Pakistan

$\begin{array}{ll}\text { Abbreviations } \\ \text { WBDF } & \text { Water-based drilling fluid } \\ \text { SBMS } & \text { Synthetic based mud system } \\ \text { LDSM } & \text { Linear dynamic swell meter } \\ \text { CEC } & \text { Cation exchange capacity } \\ A & \text { Saturation swelling volume } \\ B & \text { First order rate parameter } \\ C & \text { Filtrate loss parameter } \\ t & \text { Time in (h) } \\ S & \text { Swelling percentage } \\ C & \text { Clay content } \\ T & \text { Temperature }\left({ }^{\circ} \mathrm{C}\right) \\ \text { MAE } & \text { Mean absolute error } \\ \text { MSE } & \text { Mean square error } \\ \text { RMSE } & \text { Root mean square error } \\ n & \text { Temperature exponent } \\ a_{1} & \text { Tuning parameter } \\ a_{2} & \text { Universal constant }\end{array}$




\section{Introduction}

Drilling fluid is considered as one of the most important segment in drilling industry. It is used in the oil and gas sector to provide numerous functions such as removal of the drill cutting, cool and lubricate the bit (Zakaria 2013; Al-Yasiri et al. 2019; Bayata et al. 2018; Abdo and Haneef 2011; Mao et al. 2015), maintain hydrostatic pressure, and assist in well logging operations (Zakaria 2013; Al-Yasiri et al. 2019; Abdo and Haneef 2011; Mao et al. 2015). Drilling fluid can be classified into three distinct categories, water-based drilling fluid (WBDF), oil-based drilling fluid and syntheticbased mud systems (SBMS) (Bayata et al. 2018). Though the latter two have some high operational competences, yet still their use decline considerably because of environmental issues associated with them (Bayata et al. 2018; Riley et al. 2012; Sharma et al. 2012; Khodja et al. 2010). As a result, the use of WBDF is preferred, despite suffering from some shortcomings. However, main drawback accompanied with the use of WBDF is drilling in a shale formation. This formation tends to swells when comes directly in contact with WBDF (Bayata et al. 2018; Aftab et al. 2020a; Al-Ansari et al. 2017). However, still almost $75 \%$ of the shale formations are drilled using WBDF (Aftab et al. 2020a; Murtaza et al. 2020) because this mud system is fairly inexpensive (Aftab et al. 2020a; Elkatatny et al. 2018) and environmentally friendly (Aftab et al. 2020a; Aftab et al.2017a; Murtaza et al. 2020).

Shale is mainly classified as a clastic sedimentary rock (Díaz-Pérez et al. 2007), which comprises of silt, clay and mud in varying concentrations (Gholami et al. 2018; Moslemizadeh et al. 2015; Wang et al. 2020). The concentration of the clay mineral in shale formation is arranged either in the form of lamination (Díaz-Pérez et al. 2007; Moslemizadeh et al. 2015), structural or dispersed. Almost $90 \%$ of wellbore instability problem are as a result of these high clay contents (Moslemizadeh et al. 2015; Steiger and Leung 1992). The clay minerals consist of crystal platelets that are tetrahedral and octahedral in shape and are linked with oxygen atoms (Moslemizadeh et al. 2015). Swelling and disintegration of clay normally arises as a result of the weak bonding between different tetrahedral sheets (Gholami et al. 2018), Van der Waals attraction and the in situ stresses (Oort 2003). Based on the structure of these sheets and their surface charges, clay mineral is classified into three different groups such as kaolinite, illite and montmorillonite (Aftab et al. 2017a). Out of these three minerals, montmorillonite have the greatest tendency to swell because of the wide gap that exists between its platelets (Moslemizadeh et al. 2015; Aftab et al. 2020b; Aftab et al. 2017b). This clay mineral expands up to ten times of its original size (Swai 2020), thus, exhibits wellbore instabilities issues, which ultimately results in severe consequences in the form of loss of life or even abandonment of the well (Swai 2020).

Several researchers experimentally reveal the swelling characteristics of shale formation. Darley in 1969 studied the swelling and dispersion of shale (Maghrabi et al. 2013). Similarly, in 1989 Chenevert and co-workers studied the inhibition of shale when it comes in contact with WBDF under both ambient and downhole conditions (Maghrabi et al. 2013). It was recommended during their study that for the prediction of early time swelling-indicator test was the best (Chenevert and Osisanya 1989). Furthermore, CEC test was conducted for the determination of exchangeable ions in the shale rock (Chenevert and Osisanya 1989). Stowe et al. (2001) and Ghanbari and Naderifar (2016), perform the experimentation on the stability of shale matrix using pore pressure transmission test (Gholami et al. 2018). In recent years, the swelling of any shale formation can experimentally be determined by using linear dynamic swell meter that provides a swelling response with respect to different experimental time intervals (Maghrabi et al. 2013; Samir and Osama 2007; Khan et al. 2020).

Likewise, the computational modeling of the swelling of shale was also studied by numerous scholars. In 1998, Molenaar formulated constitutive model based on transport equation that reveals the interaction between the drilling fluid and shale swelling (Maghrabi et al. 2013). In similar year Huang using numerical simulation and modeling demonstrates shale swelling behavior when it comes in contact with the drilling fluid (Maghrabi et al. 2013). In 2003, Basma (2003) used the idea of sequential artificial neural networks to model swelling of shale sample. These neural network modeling requires extensive computation works, for that purpose utilization of conventional modeling techniques are always preferred. Maghrabi et al. in 2013 developed a time-dependent equation that was found to be best fitted with the swelling response yield by linear dynamic swell meter (LDSM). The equation was derived using the first order kinetics term along with the filtration loss term (Maghrabi et al. 2013). The equation comprises of three different parameters that includes, saturation swelling term, first order swelling rate term and the filtrate loss parameter. However, the major drawback that is associated with this equation is not taking into the account the effect of temperature, swelling time, clay content that is present in the shale sample and the experimental results obtained through LDSM.

It is a well-known fact that the quality of experimental results might be affected by numerous factors; therefore, reproduction of experimental results through reliable independent modeling technique is essential. The first order kinetic model developed by Maghrabi et al. (2013) in 2013 was the fundamental model that uses concept of curve fitting for the modeling of shale swelling through linear dynamic 
swell meter experimental results. However, the model does not incorporate some of the governing factors on which the shale swelling depends. For that reason, a new proposed model that comprises of some of governing factors developed in this study. Furthermore, the major advantage for the proposed novel equation is not only it is capable of estimating swelling of shale with respect to time but also has an additional feature of predicting swelling onset time, which is not reported in any of the previous studies conducted on shale sample. The novel equations and previously developed model are applied on the experimental datasets and performance analysis of both equations is carried out using graphical methods as well as statistical metrics and accuracies are compared.

\section{Model development}

\section{Drilling mud using in the study}

For the development of the model, one barrel of aminebased mud system was prepare in laboratory. This mud system was prepared using $303 \mathrm{~mL}$ of water in which $0.25 \mathrm{~g}$ of soda ash $\left(\mathrm{Na}_{2} \mathrm{CO}_{3}\right)$ as water treatment water was added, and the mixture was stirred for $2 \mathrm{~min}$. After that, $5 \mathrm{~g}$ of PAC-L as viscosifiers was added in the mixture and the solution was again agitated for $5 \mathrm{~min}$. Next, $1 \mathrm{~g}$ of Xanthan gum as viscosifiers was added in the solution in powder form, and the solution was again blended for $5 \mathrm{~min}$. Following this, 7\% of amine solution that corresponds to $24.5 \mathrm{~mL}$ was added in the mixture. This material ensures the formation of filming layer on the metal surface that protects the metal from corrosion. Lastly, $60 \mathrm{~g}$ of barite that acts as weighing agent was added in the mud system to establish the desired mud weight. The solution was again agitated in Hamilton Beach Mixture for $30 \mathrm{~min}$ to get the desire consistency. For the validation of the model, the mud system was changed to salt polymer glycol mud system that comprises of $309 \mathrm{~mL}$ of water along with $11 \mathrm{~mL}$ of polyethylene glycol that acts as shale stabilizer and $0.5 \mathrm{~g}$ of partially hydrolyzed polyacrylamide (PHPA) in place of PAC-L. This material is used as wellbore stabilizer, which further inhibits the dispersion of clay cutting while transporting up to the surface. All the testing based on the two mud systems were performed according to API Recommended Practice 13B-1. Both the mud systems were also evaluated based on their stability. For that, both the mud system was kept at room temperature for $24 \mathrm{~h}$ in order to observe any segregation of the barite in the system. It was perceived that there was no significant change during the period of $24 \mathrm{~h}$ when the muds were at room temperature.

\section{Data preparation and linear dynamic swell meter (LDSM) test}

There are several factors that are responsible for the swelling characteristics of a shale formation. These factors include time of the interaction between the water-based drilling fluid and the shale sample, weight percentages of clay minerals especially kaolinite, illite and montmorillonite in shale sample and temperature of the environment. Therefore, for the accurate development of the model these factors are taken into the consideration. The experimental data set was collected from a research study conducted on a sample of Murree shale formation that was prepared at $8000 \mathrm{psi}$ (Lalji et al. 2021). From quantitative X-ray diffraction, it was observed that this formation comprises of $26 \%$ clay content. This $26 \%$ were further classified into $5.7 \%$ Illite, $6.7 \%$ of Kaolinite and remaining $13.6 \%$ of montmorillonite. The swelling percentage as indicated in Fig. 1 was obtained using OFITE LDSM (Model 150-80-230V). Based on the standard procedure, $15 \mathrm{~g}$ of formation was placed in a pressurized compactor at $8000 \mathrm{psi}$ for the standard time of $1.5 \mathrm{~h}$ to form pellets for testing. The swell meter cells were then properly calibrated using the standard calibration procedure. After this process, each pellet was placed in swell meter cell that comprises of $20 \mathrm{~mL}$ of drilling fluid (Lalji et al. 2021). Similar procedure was followed for the Khadro formation that is used for the validation of the proposed model. This formation was acquired from the study of Khan et al. (2020) and was prepared at 6000 psi. Figure 2 indicates the swelling percentage of Khadro formation obtained using OFITE LDSM. This formation also comprises of $26 \%$ clay content that was further subdivided into $11 \%$ of Montmorillonite, $9 \%$ of Kaolinite and 6\% of Illite (Khan et al. 2020). The effect of stresses and pressure were not studied during the experimentation. As mainly linear dynamic swell meter works on the concept of deducing the change in height of the sample through the use of transducer.

\section{First-order kinetic model for swelling model (EXISTING MODEL)}

This existing method for the modeling of LDSM test results was developed in 2013 by Maghrabi et al. (2013). The equation for the shale swelling was derived by using the saturation swelling volume denoted by $\mathrm{A}$, first order swelling rate denoted by $\mathrm{B}$, which shows the number of available positions for swelling to progress and filtration loss parameter indicated by symbol C (Maghrabi et al. 2013). Equation (1) shows the Maghrabi et al. equation for the swelling

$$
\% S(t)=A\left(1-\frac{1}{e^{B t}+C \sqrt{t}}\right)
$$


Fig. 1 Swelling percentage of Murree shale formation obtained from linear dynamic swell meter (Lalji et al. 2021)
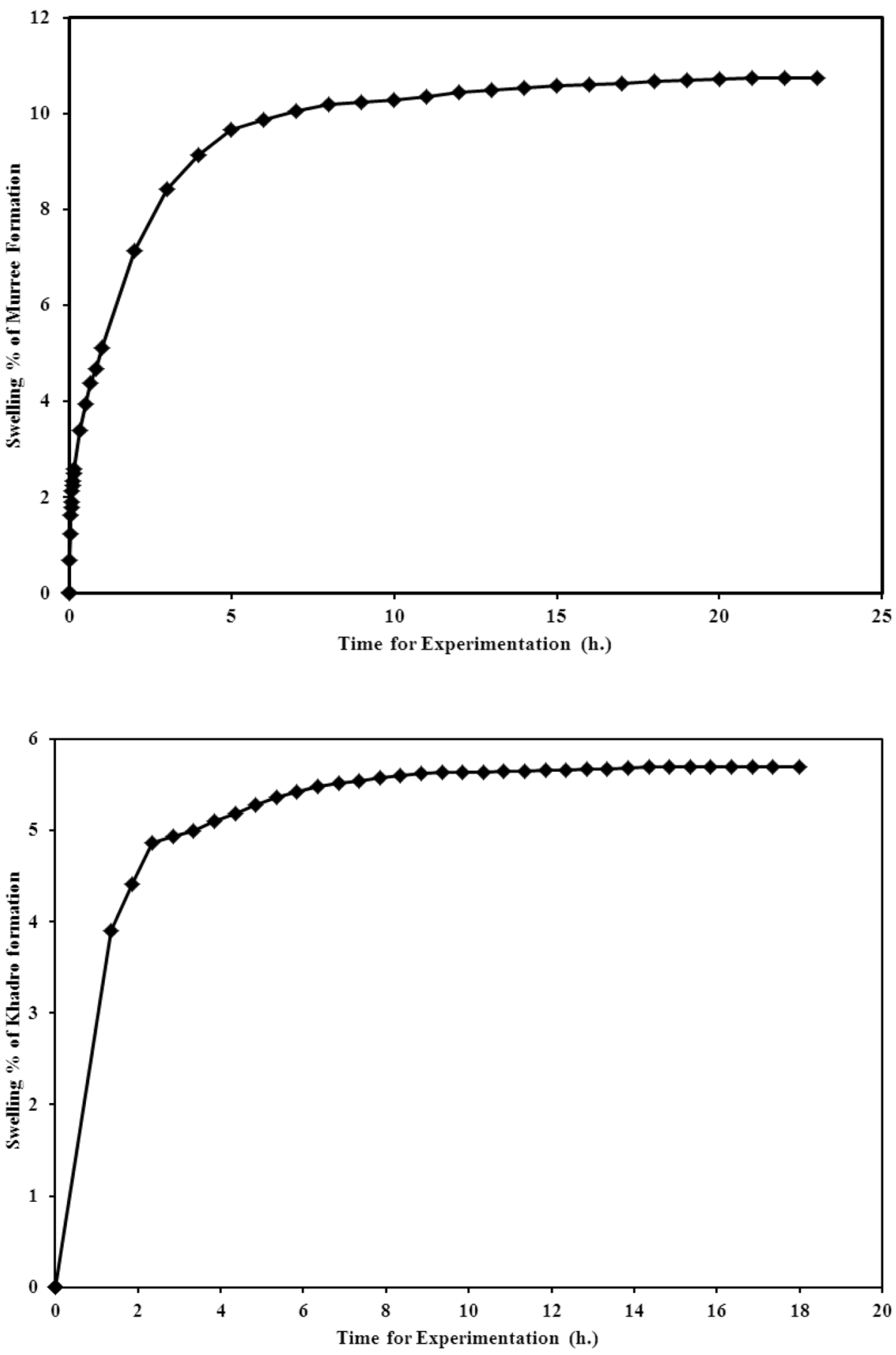

Fig. 2 Swelling percentage of Khadro shale formation obtained from linear dynamic swell meter (Khan 2020)
The swelling characteristics parameters A, B and C are attained by fitting the Eq. (1) on the curve of linear dynamic swell meter experimental results (Maghrabi et al. 2013). Here, the saturation swelling volume (A) is dependent on the cation exchange capacity (CEC) of the shale sample and the first order rate parameter (B) is reliant on the viscosity of the water-based mud system. While the filtrate loss parameter denoted as $(C)$ was assigned a value between 0 and 1 , since this parameter significantly contributes during the early stage of contact between the mud and shale sample
(Maghrabi et al. 2013). The above-mentioned parameters are generally called as tuning parameters, which are modified according to the composition of water-based drilling fluid. As a matter of fact, as shown in Fig. 3, when this first order kinetic model was used to verify the quality of the results for the Pakistan shale formation, it was found out that swelling results were not in good agreement with the experimental datasets. The difference between the two datasets was because of missing of some of the vitals parameters in the modeling equation. These parameters include clay contents, 
Fig. 3 Modeling of Pakistan's shale formation using first order kinetic equation

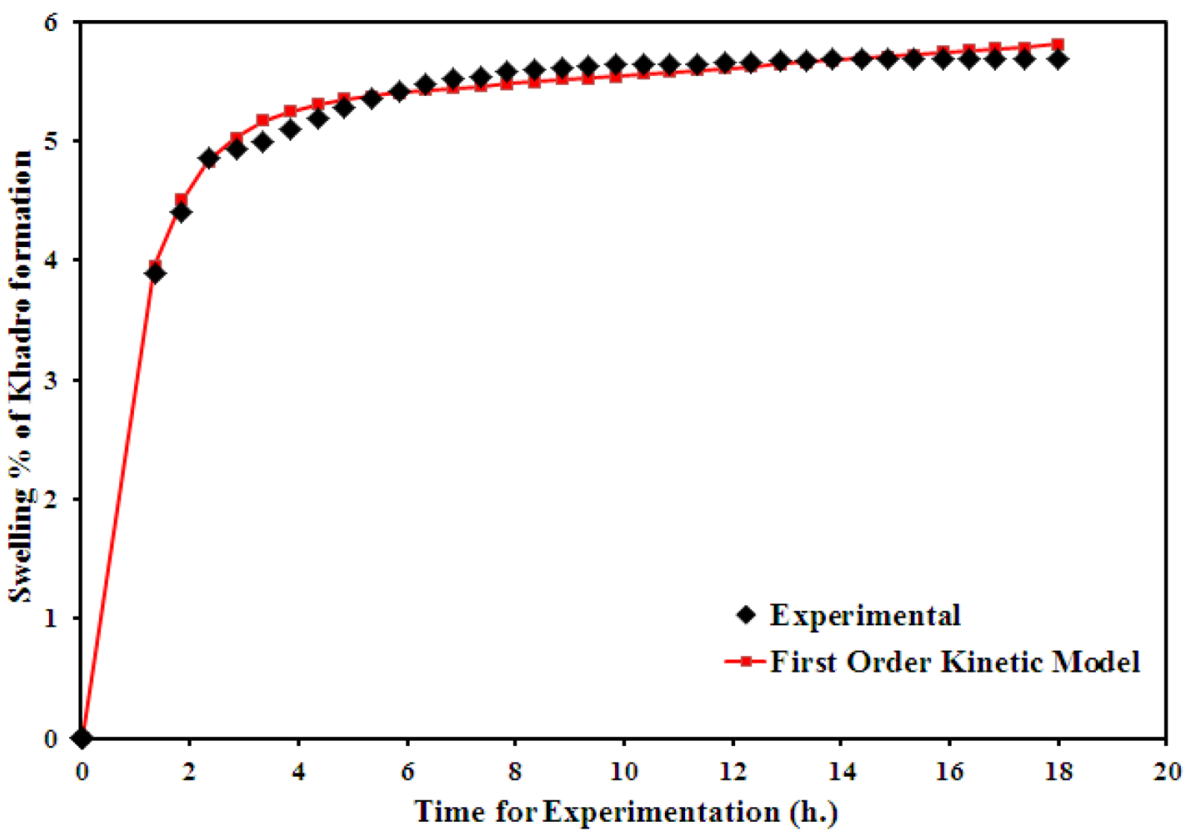

temperature and the experimental results obtained through the swell meter. As an alternative, the proposed model is derived that demonstrates a better verification of the experimental results.

\section{Proposed scaling swelling equation (NEW MODEL)}

As discussed earlier, several inadequacies are associated with previously generated model by Maghrabi et al. (2013). To resolve this issue, an attempt is made to develop a reliable model that can take into consideration all the factors which were not present in the first order kinetic equation. The proposed model is developed by taking inspiration from the approach used by scaling equation applied for modeling asphaltene precipitation in dead oils (Gholami et al. 2013). The graphs obtained in asphaltene precipitation modeling between dilution ratio and weight percent follows a similar trend as the exponential distribution curve. All the graphs start to increase at a very small dilution ratio and then get parallel with the $\mathrm{x}$-axis at higher ratio. Swelling of the shale in linear dynamic swell meter follow somewhat similar pattern. With this analogous behavior, it was suggested to use scaling model that collapse the curves of swelling rate and temperature change versus time obtained through linear dynamic swell meter into a single curve.

The main motivation features for adopting this approach are the high accuracy of scaling equations, less complexities in terms of computation, and the most importantly the similarity of experimental results (Rassamdana et al. 1996). Asphaltene precipitation is one of the major flow assurance problems of oil industry and in laboratory condition the dead oil potential to precipitate asphaltene is routinely checked by adding precipitants ( $n$-alkanes) such as n-pentane and n-hexane. Scaling equations used experimental data which mainly include dilution ratio between crude oil and precipitant, weight percentage of asphaltene precipitated, experiment temperature and precipitant molecular weight. Though, the first scaling equation was developed by Rassamdana et al. (1996) in 1996 but after that there are large number of scaling equation were introduced by different investigators (Jamialahmadi and Ahmadi 2003). In this study, the approach applied by Ashoori et al. is adopted (Jamialahmadi and Ahmadi 2003). Ashoori et al. used four experimental parameters to model asphaltene precipitation which include precipitant molecular weight (asphaltene promoter), experimental temperature (less sensitivity on precipitation), dilution ratio of precipitant to oil that is considered to be directly proportional to precipitation till certain ratio and then become constant, and the weight percent of experimental precipitated asphaltene (final outcome).

During this study, three of the variables were monitored during the experimentation of shale swelling through OFITE LDSM. These parameters are experimentation time, temperature of the cell and the swelling percentages of the shale sample during its contact with the mud. However, a fourth parameter specifically the clay content, which is associated with the shale rock, was also determined during the study through QXRD reports. Since the linear dynamic swell meter experiment was performed at room temperature hence, temperature during the modeling was consider less sensitive as it do not changes significantly during experimentation. Furthermore, if a shale sample is tested at a temperature

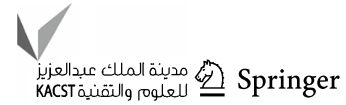


greater than $0{ }^{\circ} \mathrm{C}$ it demonstrates a lower swelling potential than those tested at a temperature below $0{ }^{\circ} \mathrm{C}$ (Huang et al. 1995). Moreover, the clay content was also made part of this model. This content is basically the aggregate of all the clay minerals weight percent obtained through QXRD reports. It is generally observed that greater the percentage of the clay content more will be the swelling in the shale sample; hence, for this particular reason it was made part of the model. Lastly, since the experimentation performed through the use of linear dynamic swell meter that is monitoring the result based on time, therefore, the use of contact time between the mud and shale sample was also made part of this equation.

To develop the proposed scaling swelling equation the four parameters are combined into two new variables $X$ and $Y$ as given below in Eqs. (2) and (3). Here $t, T, C$ and $S$ represents time, temperature, clay content and experimental swelling percentage obtained through OFITE LDSM and QXRD reports respectively.

$X=\frac{t}{T^{n} * C^{a_{1}}}$

$Y=\frac{S}{t^{a_{2}}}$

Moreover, $\mathrm{a}_{1}$ and $\mathrm{n}$ are the adjustable parameters while $a_{2}=-2$ is defined as a universal constant. All these are finetuning parameters that are selected for the purpose of achieving good fitting modeling results of the experimental data. The experimental data that comprises of swelling percentages vs. time and temperature of the experiment vs. time is collapsed on a single curve represented between two variables namely $X$ and $Y$ as shown in Eqs. (2) and (3), which is epitomized very accurately by third degree polynomial as shown in Eq. (4). This equation is used to back calculate the experimental data of the linear swell meter. It was observed that a higher or lower polynomial equation than this Eq. (4) do not provide an appropriate fitting curve that corresponds to linear dynamic swell meter experimental results.

$A_{1}, A_{2}, A_{3}$ and $A_{4}$ in this equation are classified as scaling equation coefficients and $X_{c}$ is the value of $X$ at the onset/ swelling initiation point of shale swelling. In order to obtain the onset point of swelling, the $X_{c}$ need to be determined by substituting $Y$ a value of 0 and then performing back calculation to obtain the $t_{c}$ (critical time). Critical time is the time at which swelling starts. To improve the performance of proposed model, the collapsing of data is done by splitting the dataset in terms of time. The splitting point is selected by looking at the behavior of curve between time and swelling. The time at which swelling increases abruptly is taken as splitting point. In this work, the splitting of experimental data is done at $1 \mathrm{~h}$. Figure 4 shows the workflow for the proposed model developed in this study.

$Y=A_{4}+A_{3} X+A_{2} X^{2}+A_{1} X^{3} \quad X \geq X_{c}$

\section{Performance evaluation of proposed scaling swelling equation}

The performance of the proposed scaling swelling equation is evaluated using mean absolute error (MAE), mean square error and the root mean square error. The value of MAE, MSE and RMSE has been computed using Eqs. (5) to (7),
Fig. 4 Workflow of the proposed scaling swelling model

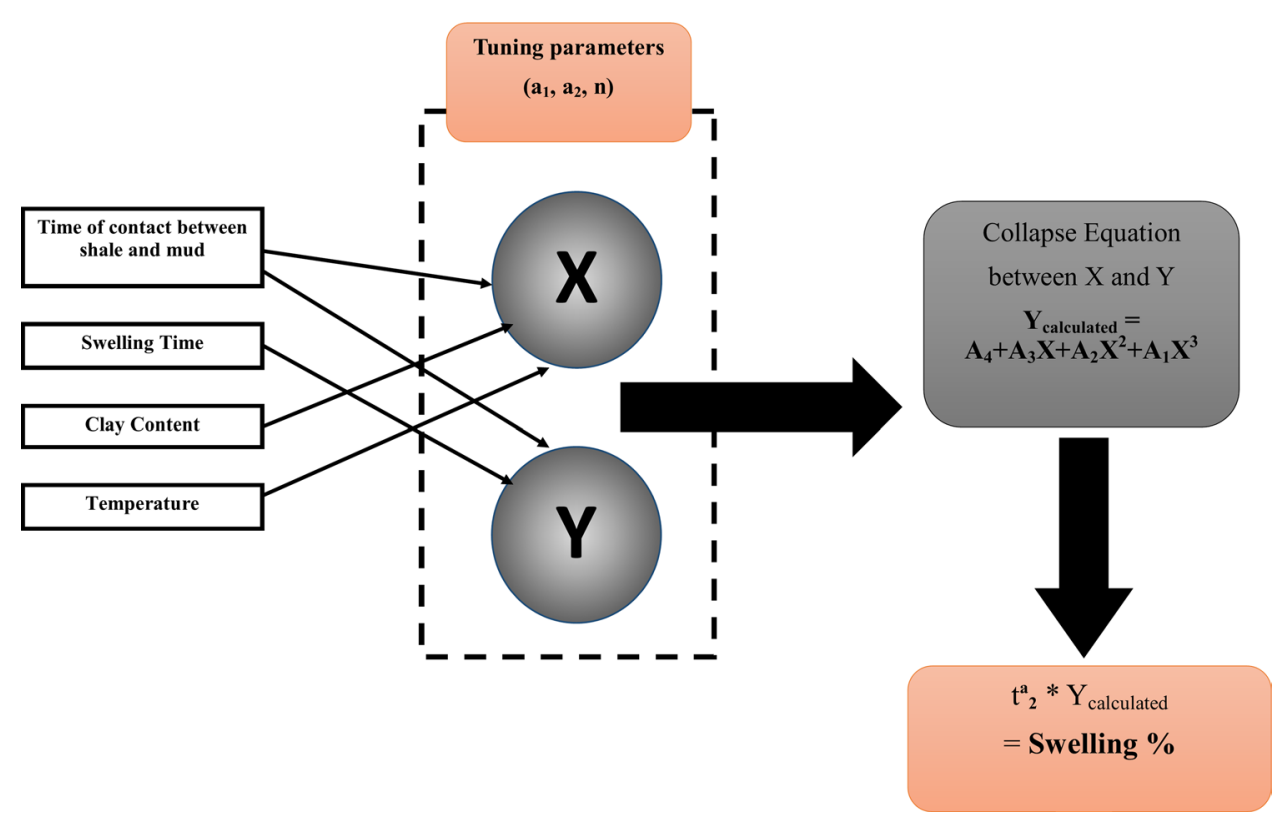


(a)

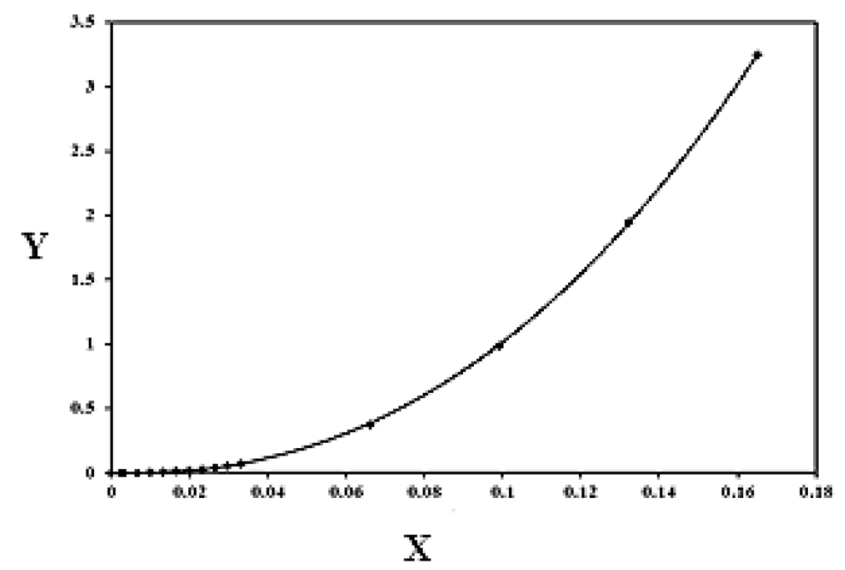

(b)

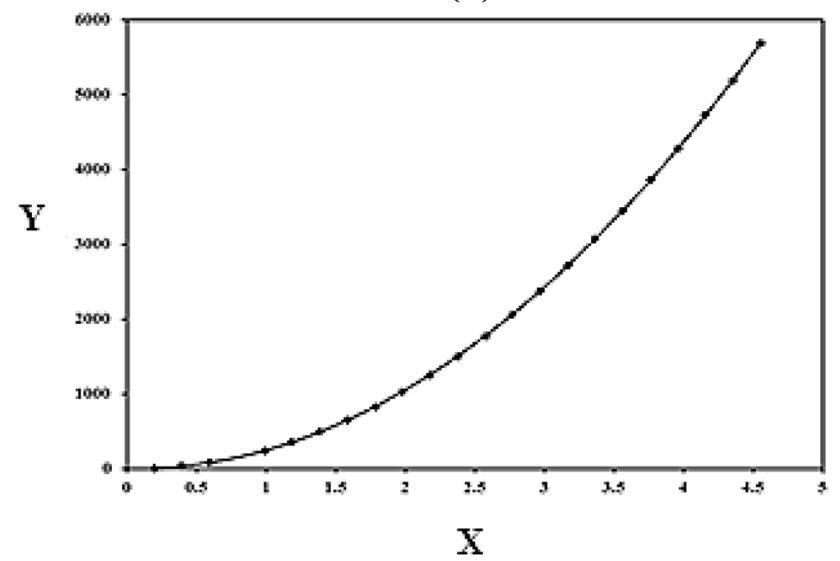

Fig. 5 Collapse of swelling experimental data onto polynomial curve using the proposed scaling swelling equation a swelling is dominant $\mathbf{b}$ swelling is subservient

Table 1 Coefficient of the collapse equation between $\mathrm{X}$ and $\mathrm{Y}$

\begin{tabular}{llrlll}
\hline Region & $\mathrm{A}_{1}$ & \multicolumn{1}{c}{$\mathrm{A}_{2}$} & \multicolumn{1}{c}{$\mathrm{A}_{3}$} & $\mathrm{~A}_{4}$ & $\mathrm{R}^{2}$ \\
\hline$<1 \mathrm{~h}$ & 192.043 & 95.701 & -1.383 & 0.006 & 0.989 \\
$>1 \mathrm{~h}$ & -0.216 & 285.223 & -46.802 & 7.123 & \\
\hline
\end{tabular}

where $N$ is the number of data points, $y_{i}$ is the calculated value and $\widehat{y_{i}}$ is the experimental value (Ali et al. 2021).

$\mathrm{MAE}=\frac{1}{N} \sum_{i=1}^{N}\left|y_{i}-\hat{y}_{i}\right|$
$\operatorname{MSE}=\frac{1}{N} \sum_{i=1}^{N}\left(y_{i}-\widehat{y_{i}}\right)^{2}$

$\mathrm{RMSE}=\sqrt{\mathrm{MSE}}$

For the in-depth study of the proposed scaling swelling equation, two graphical analyses techniques have been used. First a cross-plot is generated, which shows the relationship between the predicted values and the actual values. This plot comprises of a unit slope line that is established as a perfect model line (Ali et al. 2021). The accuracy of the predicted model can be determined if a higher percentage of the data points fall on to this perfect model line. Secondly, a relative error plot is generated, which determines the deviation between the predicted results obtained from the proposed
Fig. 6 Sensitivity analysis for different $a_{1}$ values

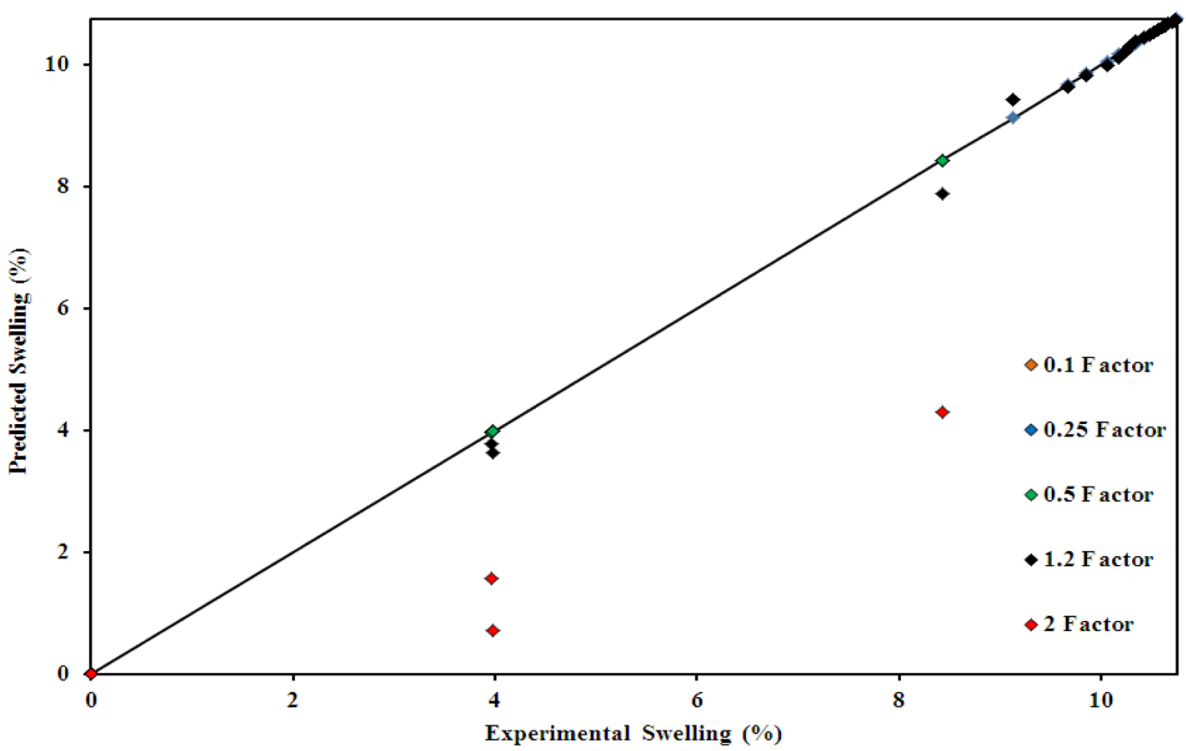


Fig. 7 Sensitivity analysis for temperature coefficient ' $n$ '

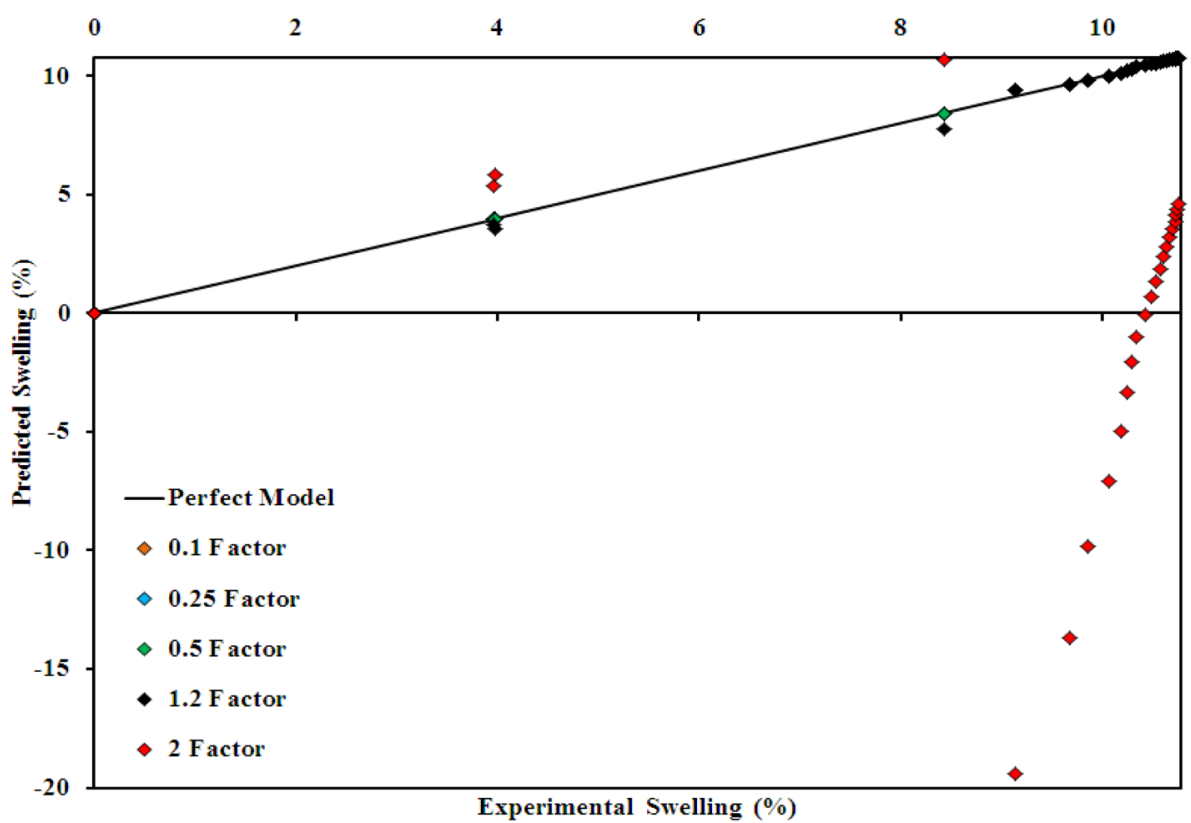

model and the actual experimental results collected from linear dynamic swell meter results. The closer the peaks are to the $\mathrm{x}$-axis the more consistency will be there between the model and experimental results.
Table 2 Final Swelling \% result

Experimental result First order kinetic model

$\begin{array}{lll}10.75 & 10.60 & 10.75\end{array}$

Fig. 8 Swelling results from obtained from experimentation and modeling

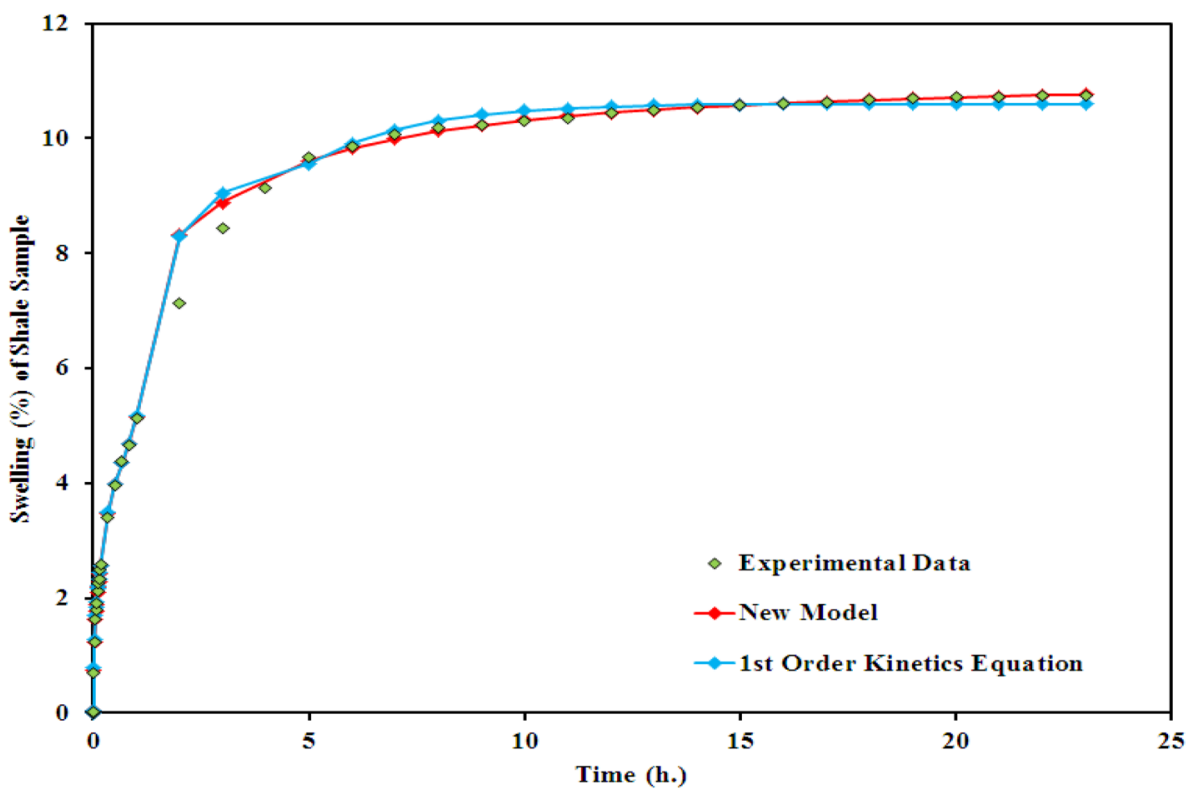


Fig. 9 Cross-plot between the different models and the experimental dataset

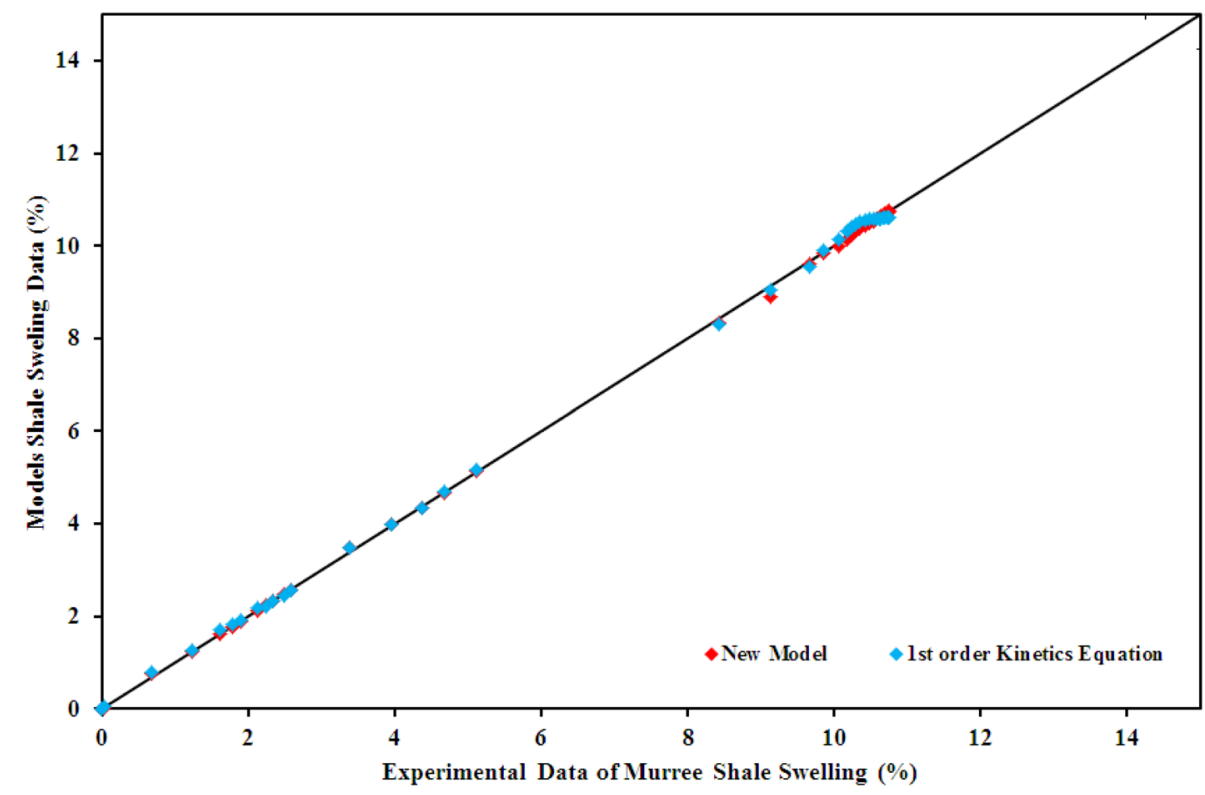

\section{Results and discussion}

\section{Implementation of the proposed scaling swelling equation}

The experiment was carried out on Murree shale formation at a temperature of $25{ }^{\circ} \mathrm{C}$. The curve shown in Fig. $5 \mathrm{a}, \mathrm{b}$ represents a third degree polynomial relationship established between the two variables $X$ and $Y$ using Eq. (4). In the definition of $X$ and $Y$, the temperature exponent ' $n$ ' and the parameter $a_{1}$ in Eq. (2) are denoted as adjustable parameters that can be tuned depending upon the type of mud used in swelling experiment. Both of these parameters values lies within a range of 0.1 to 0.5 . The coefficient $a_{2}$ in Eq. (3) is treated as a universal constant having a value of -2 as already discussed in previous section. The collapse equation obtained between $X$ and $Y$ is shown in Eq. (4).

It was observed from Fig. 1 that the maximum swelling occurred during the first few hours of the contact between the drilling mud and the shale sample; therefore, the swelling data was divided into two different regions with respect to swelling time. Figure 5a exhibits the region where swelling was dominant, while on the other hand, Fig. 5b displays the region where swelling was subservient. This division further improves the modeling results for the proposed model, as it was observed that both the cases reported a good fitting behavior. The best adjustable parameters in this case were obtained through MATLAB optimization tool, which ensures the accuracy of the proposed model by minimizing the error percentages. The variables in Eq. (2) were tuned with the values of $a_{1}=0.25$ and $n=0.25$ respectively. Table 1 shows the coefficient values of the collapse equation found for two cases after tuning the adjustable parameters. It was further observed that the value of $R^{2}$ for both cases was close to 1 , which is indicating the most appropriate fitting behavior relationship between the two variables $X$ and $Y$.

Figures 6 and 7 show the sensitivity of adjustable parameters on the swelling percentages results. It was observed that increase in values of these adjustable parameters shows the deviation of the swelling result from the perfect model line. For this particular case, the optimum values for the adjustable parameters are in range of 0.1-0.5. Furthermore, it was witness that if the values of $a_{1}$ and ' $n$ ' increases to 2 , then negative swelling percentages were obtained, which indicates the poor performance of the proposed model. It was observed that when the values of adjustable parameters go beyond 0.5 or below 0.1 , the parameters $X$ and $Y$ were not reporting a good fitting behavior. Therefore, when the collapse equation as shown by Eq. (4) was formed for those cases it was witnessed that $R^{2}$ value was very low, thus, indicating a very small percentage of data sets falling on the perfect model line. Hence, it was concluded that the values of " $a_{1}$ " and " $n$ " lies within the window of $0.1-0.5$.

Figure 8 illustrates the swelling curve obtained from the experimental result, proposed model and the first order kinetic equation. It can be recognized from the figure that the proposed model almost produces a replica of the experimental results. It can further observed from Table 2 that the first order kinetic model under predict the final swelling result, which is not apparent for the proposed model. A deviation of $1.40 \%$ was observed in the final swelling result for the first order kinetic. On the other hand, for the new proposed model the final swelling result obtained shows concurrency with the experimentation results obtained from LDSM. 
Fig. 10 Relative error yield by applied models while predicting swelling at different time intervals

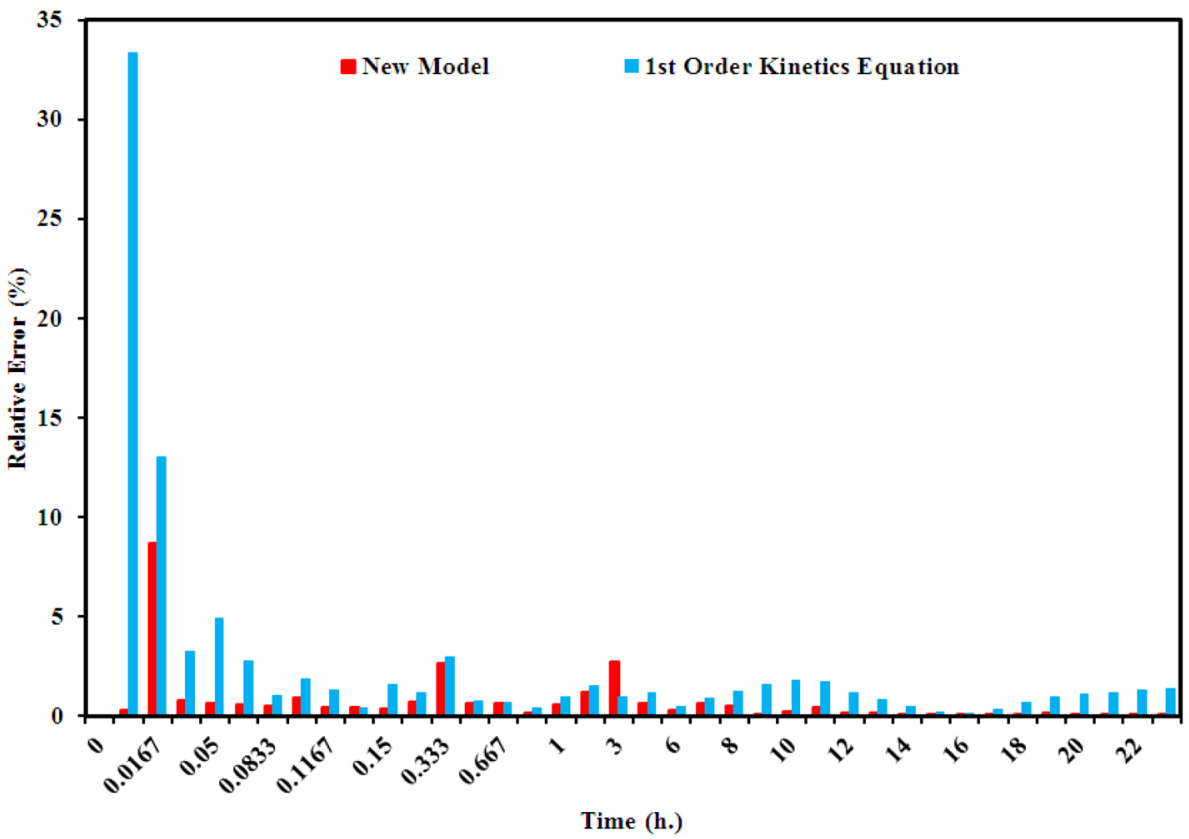

\section{Model accuracy}

Figure 9 depicts the graphical demonstration of cross-plot for the swelling percentages obtained through two different models. It can be perceived from the result that for the new proposed model, a large portion of the datasets fall on the perfect model line, which clearly indicates the preeminence of the proposed model over the first order kinetic equation.

To quantify the difference in behavior of the two models a relative error plot of two models can be seen in Fig. 10, which exhibits the predicting swelling results with respect to time of the experiment. It can be observed that the first order kinetic equation demonstrates higher percentages of the relative error; while for the new proposed model the sizes of the relative errors histogram are very small, thus indicating an excellent performance. For the new model, at initial time interval the value of the relative error is maximum, however, this value does not significantly contributes to the overall error in the model. For the new model, it can further observed that out of 38 dataset points only a single point lies outside the relative error of $5 \%$. This clearly indicates that the swelling percentages obtained under this model as relatively closer to the experimental results from the linear dynamic swell meter.

The overall error can be witnessed in Fig. 11, where errors from both the models are calculated for comparison. It can be claimed that the new model produces error somewhat half of the first order kinetics equation. The values of MAE, MSE and RMSE are calculated using the Eqs. (5) to (7). As a rule of thumb, minimum the values of these three error source higher will be the accuracy of the model. It can be recognized that the new model only produces a

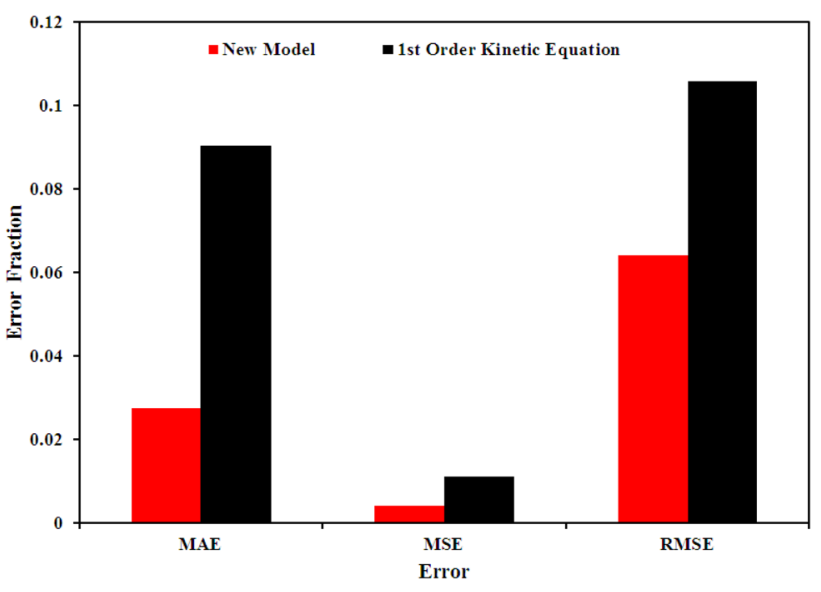

Fig. 11 Error comparison bar charts between two model

MAE value of $2.75 \%$ while, the existing model develops an error of $9.03 \%$. This analysis clearly indicates that the curve extracted from the new model covers the swell meter results with less discrepancy.

\section{Validation of the proposed model}

In order to confirm the correctness of the new model, it was applied on Khadro formation results gathered from Khan et al. (2020). This formation exhibits a maximum swelling percentage of $5.7 \%$ after the recommended testing practice. The temperature under which the testing was done was equal to $32{ }^{\circ} \mathrm{C}$. The clay content present in this formation was $26 \%$ (Khan et al. 2020).The goal is to validate the performance of the model on the other type of shale that comprises of 
Table 3 Coefficient of $\mathrm{X}$ and $\mathrm{Y}$ of the collapse equation for the Khadro formation

\begin{tabular}{llllll}
\hline Region & $\mathrm{A}_{1}$ & $\mathrm{~A}_{2}$ & $\mathrm{~A}_{3}$ & $\mathrm{~A}_{4}$ & $\mathrm{R}^{2}$ \\
\hline$<1 \mathrm{~h}$ & 207.530 & 59.438 & -1.027 & 0.006 & 0.979 \\
$>1 \mathrm{~h}$ & -1.449 & 174.625 & -17.844 & 0.276 & 0.987 \\
\hline
\end{tabular}

Fig. 12 Cross-plot for the validation of Khadro formation obtained by using proposed model

Fig.13 Relative error bar graphs for Khadro formation swelling obtained by using proposed model different clay percentages, swelling and temperature. A total of 62 points were selected from the experimental data for the validation purpose. Table 3 shows the coefficient values for the adjustable parameters that were obtained after tuning the model. Again the model was divided into two separate regions for the higher accuracy. It can be seen that in both the regions the $R^{2}$ is equal to or closer to 1 . According to the
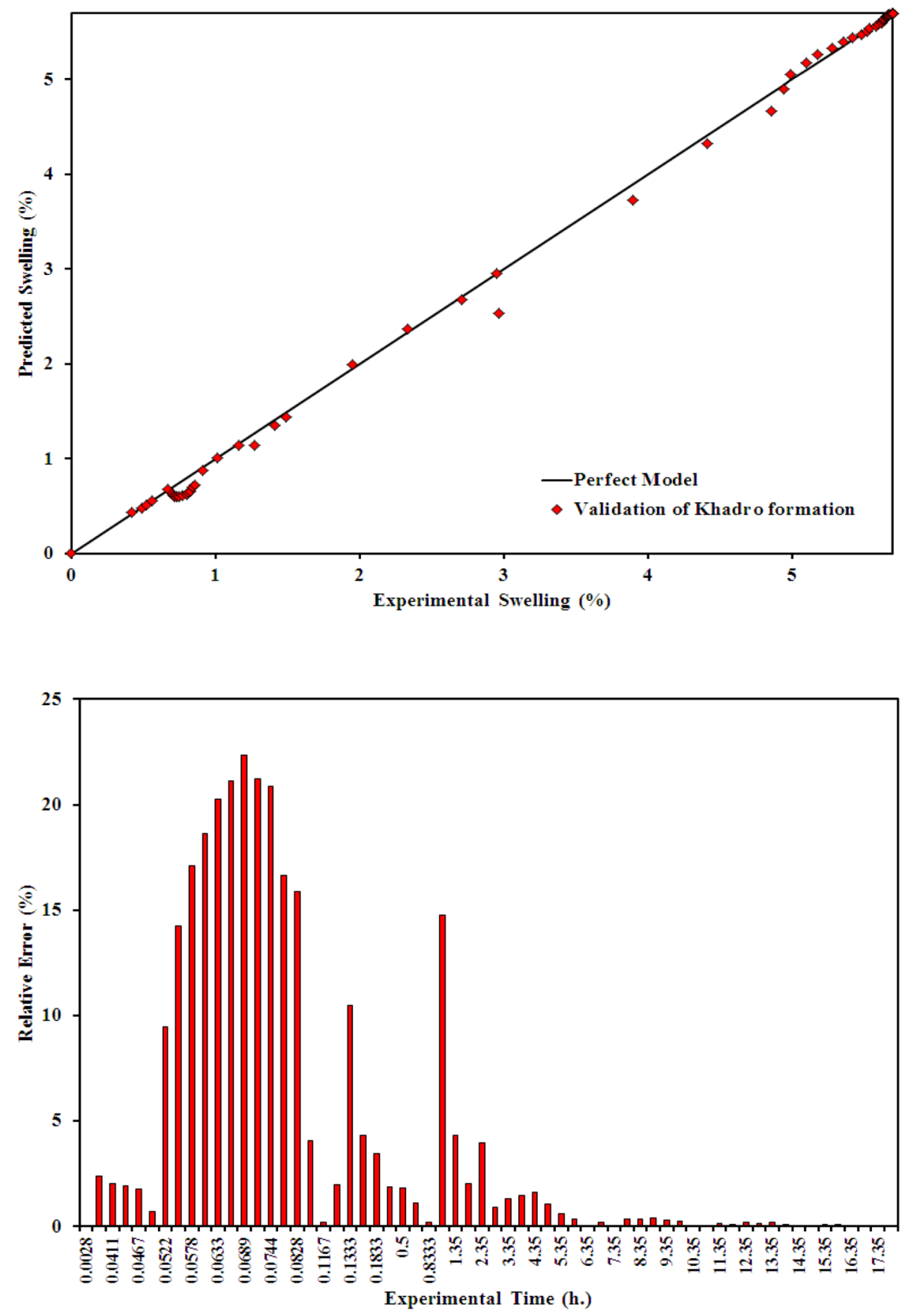
Table 4 Error \% obtained from the implementation of proposed model on Khadro formation

\begin{tabular}{ll}
\hline Error & Percentage (\%) \\
\hline Mean absolute error (MAE) & 5.54 \\
Mean square error (MSE) & 0.88 \\
Root mean square error (RMSE) & 9.40 \\
\hline
\end{tabular}

definition, if the value of $R^{2}$ is equal to 1 then it indicates a relatively higher accuracy of the fitting curve correlation.

Figure 12 shows the cross-plot for the validation of the model. It can be seen that the model is again validating a comparatively good performance for this formation. The swelling results obtain for this formation all falls around the perfect model line thus indicating the correctness of
Fig. 14 Zoom view of the predicted swelling critical time for Murree formation
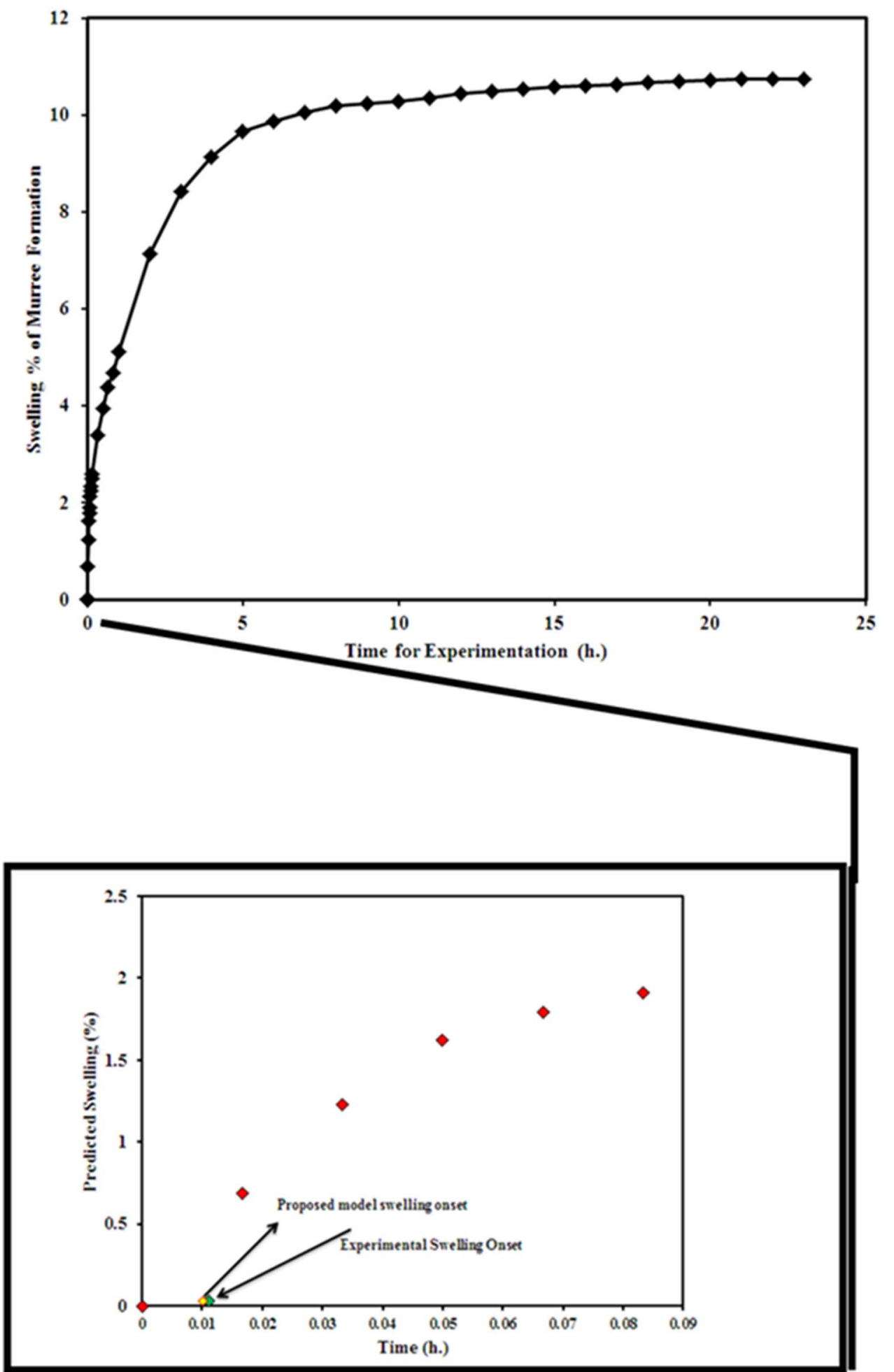
Fig. 15 Zoom view of the predicted swelling critical time of Khadro formation

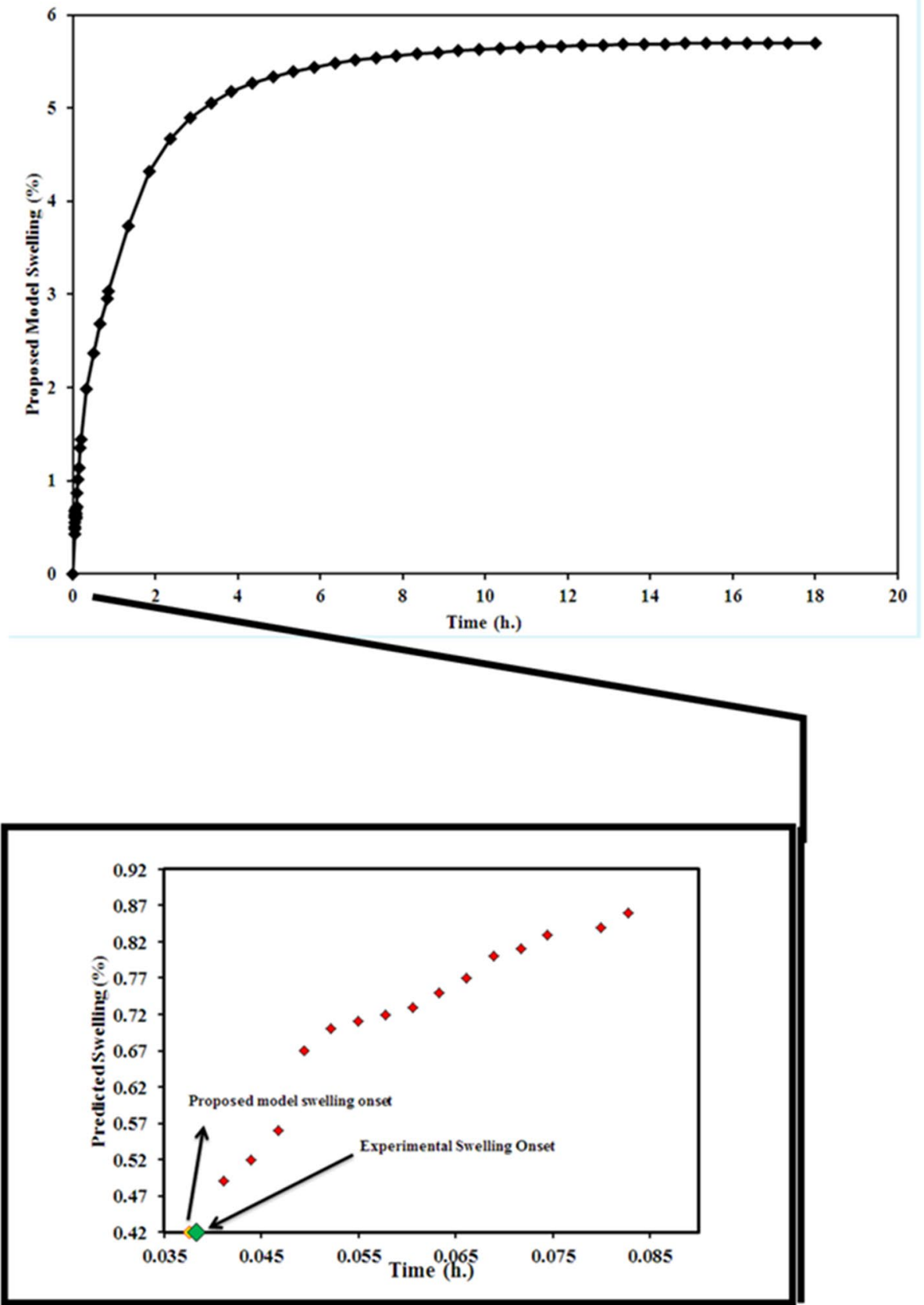

Table 5 Swelling critical time for both datasets

\begin{tabular}{llll}
\hline Formation & Experimental & Predicted & \% deviation \\
\hline Murree & 0.011 & 0.010 & 9.999 \\
Khadro & 0.038 & 0.035 & 7.895 \\
\hline
\end{tabular}

the proposed numerical model. The validation was further enhanced by the relative error plot as shown in Fig. 13. From this figure it is apparent that error lies within $+25 \%$ making it a sound justification for the validation. Finally, to prove the efficiency of the model, Table 4 shows the values of different error sources. It can be observed that the model exhibits fairly small error percentages while predicting the swelling of the formation. This proves the accuracy of the proposed model in predicting the swelling of a shale formation.

\section{Swelling onset determination using proposed model for both datasets}

The initiation of swelling for a shale formation is term as onset swelling point. This variable is denoted as ' $t_{c}$ ' in Eq. (2). It is basically the contact time at which the swelling of shale formation commence when it comes directly 
in contact with a drilling fluid. Figure 14 shows the critical time for the initiation of swelling in Murree formation. The green point in the zoom view illustrating the experimental onset point of the swelling in this formation, whereas, for the proposed model it can be witnessed from the yellow point that the prediction of $t_{c}$ is closed to the experimental result. Similarly, in Fig. 15 again green and yellow points are showing the onset swelling time for both the experimental and predicted model, respectively. It can be observed that both points are again very close to one another. Table 5 shows the percentage deviation between the critical time for the swelling results. It is apparent from the result that in either of the two cases the deviation is less than $10 \%$, which indicates a good performance by the proposed model.

\section{Conclusion}

Linear dynamic swell meter response was modeled successfully in this article. The formulation process of the model equation is a simple and direct and is basically dependent on the quantity of the clay content present in a shale sample, time of contact between the mud and the formation, response of experimental result and finally the temperature. Two disparate Pakistan's shale formations obtained from two different regions were used for the development and validation of the model. It was observed that this proposed model is far better than conventional modeling techniques in modeling the response of the experimental results. The proposed model consists of tuning parameters. Integrity of these parameters depends upon the type of mud that is been in contact with the shale sample. Errors below $10 \%$ were obtained through the fine-tuning of these parameters that result in a better prediction of the swell meter experimental results. Moreover, it was envisioned that the information obtained from the equation helps in predicting the swelling initiation time when the mud and shale comes in direct contact with each other. This information is extremely helpful in forecasting and validating the swelling tendency of the shale sample in a particular mud.

Funding No funding agency is involved in this research article.

\section{Declaration}

Conflict of interest The authors report no conflict of interest.

Open Access This article is licensed under a Creative Commons Attribution 4.0 International License, which permits use, sharing, adaptation, distribution and reproduction in any medium or format, as long as you give appropriate credit to the original author(s) and the source, provide a link to the Creative Commons licence, and indicate if changes were made. The images or other third party material in this article are included in the article's Creative Commons licence, unless indicated otherwise in a credit line to the material. If material is not included in the article's Creative Commons licence and your intended use is not permitted by statutory regulation or exceeds the permitted use, you will need to obtain permission directly from the copyright holder. To view a copy of this licence, visit http://creativecommons.org/licenses/by/4.0/.

\section{References}

Abdo J, Haneef MD (2011) Nano-enhanced drilling fluids: pioneering approach to overcome uncompromising drilling problems. $\mathrm{J}$ Energy Resour Technol 134(1)

Aftab A et al (2017a) Nanoparticles based drilling muds a solution to drill elevated temperature wells: a review. Renew Sustain Energy Rev 76:1301-1313

Aftab A, Ismail AR, Ibupoto ZH (2017b) Enhancing the rheological properties and shale inhibition behavior of water-based mud using nanosilica, multi-walled carbon nanotube, and graphene nanoplatelet. Egy J Petrol 26(2):291-299

Aftab A et al (2020a) Environmental friendliness and high performance of multifunctional tween $80 / \mathrm{ZnO}$-nanoparticles-added waterbased drilling fluid: an experimental approach. ACS Sustain Chem Eng 8:11224-11243

Aftab A et al (2020b) Influence of tailor-made $\mathrm{TiO}_{2} / \mathrm{API}$ bentonite nanocomposite on drilling mud performance: towards enhanced drilling operations. Appl Clay Sci 199:105862

Al-Ansari A, Parra C, Abahussain A, Abuhamed AM, Pino R, El Bialy M, Mohamed H, Carlos L (2017) Reservoir drill-in fluid minimizes fluid invasion and mitigates differential stuck pipe with improved production test results. In: Paper presented at the SPE middle east oil and gas show and conference, SPE, Editor. SPE: Manama, Kingdom of Bahrain

Ali SI, Lalji SM, Haneef J, Ahsan U, Khan MA, Yousaf N (2021) Estimation of asphaltene adsorption on $\mathrm{MgO}$ nanoparticles using ensemble learning. Chemomet Intel Lab Syst 208:104220

Al-Yasiri M, Awad A, Pervaiz S, Wen D (2019) Influence of silica nanoparticles on the functionality of water-based drilling fluids. J Petrol Sci Eng 179:504-512

Basma A (2003) Modeling time dependent swell of clays using sequential artificial neural networks. Environ Eng Geosci 9:279-288

Bayata AE, Moghanloo PJ, Pirooziana A, Rafatib R (2018) Experimental investigation of rheological and filtration properties of waterbased drilling fluids in presence of various nanoparticles. Colloids Surf A 555:256-263

Chenevert ME, Osisanya SO (1989) Shale/mud inhibition defined with rig-site methods. SPE Drill Eng 4:261-268

Díaz-Pérez A, Cortes-Monroy I, Roegiers JC (2007) The role of water/ clay interaction in the shale characterization. J Petrol Sci Eng 58(1-2):83-98

Elkatatny S, Kamal MS, Alakbari F, Mahmoud M (2018) Optimizing the rheological properties of water-based drilling fluid using clays and nanoparticles for drilling horizontal and multi-lateral wells. Appl Rheol 28(4)

Ghanbari S, Naderifar A (2016) Enhancing the physical plugging behavior of colloidal silica nanoparticles using binomial size distribution. J Nat Gas Sci Eng 30:213-220

Gholami A, Moradi S, Dabir B (2013) A power law committee scaling equation for quantitative estimation of asphaltene precipitation. Int J Sci Emerg Technol 5:275-283

Gholami R et al (2018) A review on borehole instability in active shale formations: Interactions, mechanisms and inhibitors. Earth Sci Rev 177:2-13

Huang SL, Speck RC, Wang Z (1995) The temperature effect on swelling of shales under cyclic wetting and drying. Int J Rock Mech Min Sci Geomech Abs 32(3):227-236 
Jamialahmadi M, Ahmadi K (2003) A new scaling equation for modeling of asphaltene precipitation. In: Paper presented at the Nigeria annual international conference and exhibition, SPE, Editor. Abuja, Nigeria

Khan MA et al (2020) Experimental study and modeling of waterbased fluid imbibition process in Middle and Lower Indus Basin formations of Pakistan. J Petrol Explor Prod Technol 11:425-438

Khodja MC, Canselier J, Bergaya F, Fourar K, Khodja M, Cohaut N, Benmounah A (2010) Shale problems and water-based drilling fluid optimisation in the Hassi Messaoud Algerian oil field. Appl Clay Sci 49:383-393

Lalji SM, Khan MA, Haneef J et al (2021) Nano-particles adapted drilling fluids for the swelling inhibition for the Northern region clay formation of Pakistan. Appl Nanosci

Maghrabi S, Kulkarni D, Teke K, Kulkarni SD, Dale J (2013) Modeling of shale-erosion behavior in aqueous drilling fluids. In: Paper presented at the SPE/EAGE European unconventional resources conference and exhibition, SPE, Editor. Vienna, Austria

Mao H, Qiu Z, Shen Z, Huang W (2015) Hydrophobic associated polymer based silica nanoparticles composite with core-shell structure as a filtrate reducer for drilling fluid at utra-high temperature. J Petrol Sci Eng 129:1-14

Moslemizadeh AS, Seyed R, Moomenie M (2015) Experimental investigation of the effect of henna extract on the swelling of sodium bentonite in aqueous solution. Appl Clay Sci 105:78-88

Murtaza M, Ahmad HM, Kamal MS, Hussain SMS, Mahmoud M, Patil S (2020) Evaluation of clay hydration and swelling inhibition using quaternary ammonium dicationic surfactant with phenyl linker. Molecules 25:4333

Oort EV (2003) On the physical and chemical stability of shales. J Petrol Sci Eng 38:213-235

Rassamdana H, Dabir B, Nematy M, Farhani M, Sahimi M (1996) Asphalt flocculation and deposition: I. The Onset of Precipitation Aiche J 42(1):10-22
Riley M, Stamatakis E, Young S, Price Hoelsher K, De Stefano G, Ji L, Guo Q, Jim F (2012) Wellbore stability in unconventional shale: the design of a nano-particle fluid. In: Paper presented at the SPE Oil and Gas India Conference and Exhibition. SPE: Mumbai, India

Samir AB, Osama B (2007) Custom designed water-based-mud system helped minimize hole washouts in high-temperature wells: case history from Western Desert, Egypt. In: SPE/IADC middle east drilling and technology conference

Sharma MM, Zhang R, Chenevert ME, Ji L, Guo Q, Friedheim J (2012) A new family of nanoparticle based drilling fluids. In: Paper presented at the SPE annual technical conference and exhibition. San Antonio, Texas, USA

Steiger RP, Leung PK (1992) Quantitative determination of the mechanical properties of shales. SPE Drill Eng 7:181-185

Stowe C, Halliday W, Xiang T, Morton K, Hartman S (2001) Laboratory pore pressure transmission testing of shale. In: Paper presented at the AADE national drilling conference, Texas, USA

Swai RE (2020) A review of molecular dynamics simulations in the designing of effective shale inhibitors: application for drilling with water-based drilling fluids. J Petrol Explor Prod Technol 10:3515-3532

Wang K, Jiang G, Li X, Luckham PF (2020) Study of graphene oxide to stabilize shale in water-based drilling fluids. Colloids Surf A 606:125457

Zakaria MF (2013) Nanoparticle-based drilling fluids with improved characteristics. University of Calgary, Calgary

Publisher's Note Springer Nature remains neutral with regard to jurisdictional claims in published maps and institutional affiliations. 